\title{
Neurokinin-1 Projection Cells in the Rat Dorsal Horn Receive Synaptic Contacts from Axons That Possess $\alpha_{2 \mathrm{C}}$-Adrenergic Receptors
}

\author{
M. Josune Olave and David J. Maxwell \\ Spinal Cord Group, Institute of Biomedical and Life Sciences, University of Glasgow, Glasgow G12 8QQ, United Kingdom
}

The $\alpha_{2 \mathrm{C}}$ subclass of adrenergic receptor $\left(\alpha_{2 \mathrm{C}}-\mathrm{AR}\right)$ mediates some of the antinociceptive actions of norepinephrine in the spinal cord. Axon terminals, which possess this receptor, are concentrated in the superficial dorsal horn and originate from spinal interneurons. We performed a series of combined tract-tracing and immunocytochemical studies to determine whether $\alpha_{2 \mathrm{C}}$-AR-immunoreactive axons target projection neurons that possess the neurokinin-1 (NK-1) receptor because such cells are likely to transmit nociceptive information to the brain. Spinomedullary neurons were labeled by stereotaxic injection of the B-subunit of cholera toxin (CTb) into the caudal ventrolateral medulla of three anesthetized adult rats. After $3 \mathrm{~d}$, the animals were anesthetized again and fixed by perfusion. Sections were cut from midlumbar segments and reacted with antibodies to reveal $\alpha_{2 \mathrm{C}} \mathrm{ARs}, \mathrm{CTb}$, and NK-1 receptors. Retrogradely labeled neurons possessing the NK-1 receptor $(n=45)$ were examined with confocal microscopy to investigate their relationship with $\alpha_{2 \mathrm{C}}$-ARimmunoreactive axons. Numerous $\alpha_{2 \mathrm{C}}$-AR axons were apposed to cell bodies and proximal dendrites of cells in lamina I and also to distal dendrites that originate from labeled cell bodies in lamina III/IV. A combined confocal and electron microscopic method confirmed that these appositions were synaptic. Additional experiments showed that virtually all $\alpha_{2 \mathrm{C}}$-AR terminals in contact with labeled cells are also immunoreactive for the vesicular glutamate transporter 2 and therefore are glutamatergic.

These data suggest that norepinephrine can modulate excitatory synaptic transmission from spinal interneurons to projection cells by acting at $\alpha_{2 \mathrm{C}}$-ARs. This could be one of the mechanisms that underlie the antinociceptive actions of norepinephrine.

Key words: $\alpha_{2 \mathrm{C}}$-adrenergic receptor; vesicular glutamate transporter 2; neurokinin-1 receptor; spinomedullary neurons; noradrenergic antinociception; immunocytochemistry

\section{Introduction}

Norepinephrine (NE) modulates the transmission of nociceptive information in the dorsal horn of the spinal cord and is known to induce antinociception. Pharmacological evidence indicates that this action is mediated principally through $\alpha_{2}$-adrenergic receptors ( $\alpha_{2}$-ARs) (Howe et al., 1983; Yaksh, 1985; Proudfit, 1988); these are coupled to G-proteins (Hoehn et al., 1988), which induce membrane hyperpolarization by decreasing the $\mathrm{Ca}^{2+}$ influx and increasing the $\mathrm{K}^{+}$efflux (Surprenant et al., 1990; Shen et al., 1992). Both the $\alpha_{2 \mathrm{~A}^{-}}$and $\alpha_{2 \mathrm{C}^{-}}$subclasses of adrenergic receptor are involved in NE-induced antinociception (Stone et al., 1997; Li and Eisenach, 2001; Fairbanks et al., 2002), and immunoreactivity for both receptor subclasses is concentrated in the superficial dorsal horn. Experiments using antibodies specific for the $\alpha_{2 \mathrm{~A}^{-}}$ and $\alpha_{2 \mathrm{C}}$-subclasses show that they are associated with different axonal populations (Stone et al., 1998). The $\alpha_{2 \mathrm{~A}}-\mathrm{AR}$ is found in axons that contain substance $\mathrm{P}$ and calcitonin gene-related pep-

\footnotetext{
Received April 21, 2003; revised May 27, 2003; accepted May 30, 2003.

This work was supported by a University of Glasgow Postgraduate Scholarship (M.J.0.). We thank Robert Kerr for excellent technical support and Prof. Andrew J. Todd for help and advice in this study.

Correspondence should be addressed to Dr. D. J. Maxwell, Spinal Cord Group, Institute of Biomedical and Life Sciences, West Medical Building, University of Glasgow, Glasgow G12 8QQ, UK. E-mail: david.maxwell@bio.gla.ac.uk.

Copyright $\odot 2003$ Society for Neuroscience $\quad$ 0270-6474/03/236837-10\$15.00/0
}

tide (Stone et al., 1998), which are likely to be terminals of nociceptive primary afferents (Levine et al., 1993), whereas the $\alpha_{2 C^{-}} \mathrm{AR}$ is present in axon terminals of spinal origin (Stone et al., 1998; Olave and Maxwell, 2003). Most (84\%) $\alpha_{2 \mathrm{C}}$-AR terminals are immunoreactive for the vesicular glutamate transporter 2 (VGLUT2) (Olave and Maxwell, 2003) and therefore are likely to have an excitatory action; however, a small proportion (11\%) of terminals are inhibitory and contain glutamate decarboxylase (Olave and Maxwell, 2003). Ultrastructural observations of $\alpha_{2 C^{-}}$ AR-immunoreactive axon terminals show that they form multiple synapses with large dendritic profiles in lamina I and indicate that they may target certain cells in this region (Olave and Maxwell, 2002). The identity of these target cells is not known, but if they prove to be projection neurons that are activated by nociceptive stimuli, NE could specifically inhibit excitatory polysynaptic input to such cells. This type of arrangement could be particularly important, because the $\alpha_{2 \mathrm{C}}-\mathrm{AR}$ is a potentially interesting target for selective analgesics considering that sedative effects mediated via $\alpha_{2 \mathrm{~A}}$-ARs could be avoided (Guo et al., 1999; Fairbanks et al., 2002).

The aim of the present study was to test the hypothesis that axons of excitatory interneurons possessing $\alpha_{2 \mathrm{C}}$-ARs target nociceptive projection neurons. We retrogradely labeled spinomedullary projection neurons with the B-subunit of cholera toxin 
$(\mathrm{CTb})$ and used triple immunofluorescence to examine the relationship of projection neurons that possess the substance $\mathrm{P}$ (NK-1) receptor and axons that possess $\alpha_{2 \mathrm{C}}$-ARs. Neurons of this type are likely to be involved in the transmission of nociceptive information (Naim et al., 1997; Todd et al., 2002). Furthermore, mice lacking NE display a substance $\mathrm{P}$-dependent chronic thermal hyperalgesia (Jasmin et al., 2002), which suggests that NK-1 neurons are components of the circuitry involved in NE antinociception. We also used a combined confocal and electron microscopic method to determine if $\alpha_{2 \mathrm{C}}$-AR terminals make synapses with this type of neuron and a sequential immunocytochemical method with a VGLUT2 antibody to determine if the $\alpha_{2 \mathrm{C}}$-AR terminals that contact NK-1 projection cells are likely to have an excitatory action on these cells.

\section{Materials and Methods}

Confocal microscopy. Three male Wistar rats (250 gm; Harlan, Loughborough, UK) were deeply anesthetized (ketamine/xylazine mixture, 7.33 and $0.73 \mathrm{mg} / 100$ gm, i.p.) and an aqueous solution of the CTb (1\%, 200 $\mathrm{nl}$; Sigma, Poole, Dorset, UK) was injected stereotaxically within the left caudal ventrolateral medulla (CVLM; anteroposterior, -4.8 ; dorsoventral, -0.6; mediolateral, +2.1) (Paxinos and Watson, 1997). After $3 \mathrm{~d}$, the animals were anesthetized with sodium pentobarbitone $(1 \mathrm{ml}$, i.p.) and perfused through the left ventricle with saline, followed by a fixative containing $4 \%$ formaldehyde in phosphate buffer, $\mathrm{pH}$ 7.6. The L4 lumbar segment was removed from each animal and postfixed in the same solution for $8 \mathrm{hr}$. Parasagittal sections (70 $\mu \mathrm{m}$ thick) were cut with a Vibratome. Sections were treated with $50 \%$ ethanol ( $30 \mathrm{~min}$ ) to enhance antibody penetration, which was followed by blocking in $10 \%$ normal donkey serum for $1 \mathrm{hr}$. Triple-labeling immunofluorescence was performed with a guinea pig anti- $\alpha_{2 C}-\mathrm{AR}$ antiserum (1:500; Neuromics, Minneapolis, MN; see Stone et al., 1998, for details), rabbit anti-NK-1 antiserum (1:10,000; Sigma), and goat anti-CTb antiserum (1:5,000; List Laboratories, Campbell, CA). After a $48 \mathrm{hr}$ incubation period, sections were rinsed and incubated for $3 \mathrm{hr}$ in solutions containing speciesspecific secondary antibodies coupled to the following fluorophores (all raised in donkey and diluted 1:100): rhodamine-red to identify $\alpha_{2 \mathrm{C}}$-AR immunoreactivity; fluorescein isothiocyanate (FITC) to identify NK-1 receptor immunoreactivity; and cyanine 5.18 to identify $\mathrm{CTb}$ (all obtained from Jackson ImmunoResearch, Luton, UK). Antibodies were diluted in PBS containing $0.3 \%$ Triton X-100 and $1 \%$ normal donkey serum. The sections were mounted in anti-fade medium (Vectashield; Vector Laboratories, Peterborough, UK) and stored in a freezer at $-20^{\circ} \mathrm{C}$. Double-labeled cells (i.e., retrogradely labeled cells with NK-1 receptor immunoreactivity) contralateral to the side of the injection were systematically scanned using a Bio-Rad (Hemel Hempstead, UK) MRC 1024 confocal laser scanning microscope with a $40 \times$ oil-immersion lens at $0.5 \mu \mathrm{m}$ intervals in the $z$-axis and a zoom factor of 2 . Thirty lamina I and 15 lamina III/IV neurons were reconstructed with Neurolucida for Confocal software (MicroBrightField, Colchester, VT), and appositions formed by $\alpha_{2 \mathrm{C}}$-AR axon terminals were plotted on the reconstructions. A Sholl analysis was performed to study the pattern of distribution of contacts for the two populations of neurons; numbers of contacts per 100 $\mu \mathrm{m}$ unit length of dendrite contained within concentric spheres with radii that increased at $25 \mu \mathrm{m}$ intervals from the center of the cell body were estimated.

To determine if $\alpha_{2 \mathrm{C}}$-AR contact densities on NK-1 projection cells were greater than would be expected by chance, we compared them with protein kinase $\mathrm{C} \gamma(\mathrm{PKC} \gamma)$-immunoreactive cells, which are also found in lamina I and II within the dense plexus of $\alpha_{2 \mathrm{C}}$-AR immunoreactive axons. PKC $\gamma$ cells are predominantly excitatory interneurons (Polgár et al., 1999); therefore, they would be expected to be very different functionally from NK-1 projection neurons. Triple-labeling immunofluorescence was performed as described above, except that rabbit anti-NK-1 antiserum was used in place of the rabbit anti-PKC $\gamma$ antiserum $(1: 1,000$; Santa Cruz Biotechnology, Santa Cruz, CA). Contact densities per 100 $\mu \mathrm{m}^{2}$ of dendritic surface area were calculated for lamina I and lamina

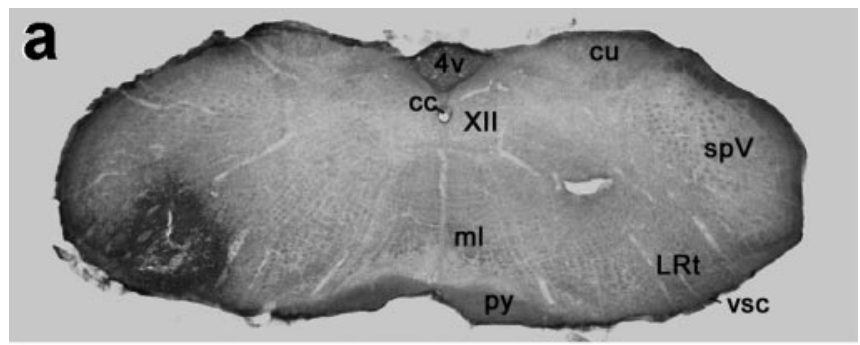

b

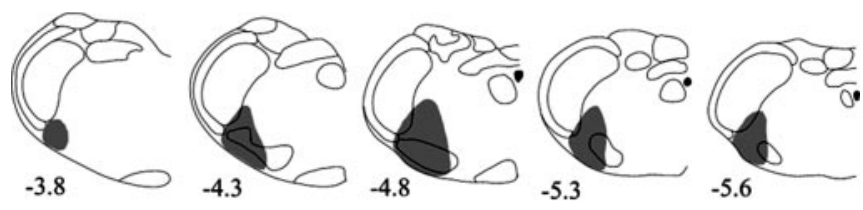

Figure 1. Injection of the retrograde tracer in the CVLM. a, Photomicrograph illustrating the CTb-injection site in the left CVLM. 4v, Fourth ventricle; cu, cuneate nucleus; cc, central canal; $\mathrm{XII}$, hypoglossal nucleus; spV, spinal trigeminal nucleus; ml, medial lemniscus; LRt, lateral reticular nucleus; vsc, ventral spinocerebellar tract; py, pyramidal tract. $b$, Reconstruction of an injection site indicating the interaural coordinate (Paxinos and Watson, 1997). The spread of the tracer is represented by the dark gray area.

III/IV NK-1 projection cells and for PKC $\gamma$-immunoreactive cells using the Neurolucida program. The average contact density was calculated for each animal ( $n=3$ on each occasion; 10 cells from each animal for lamina I and 5 cells from each animal for lamina III/IV and PKC $\gamma$ ), and the overall mean $( \pm \mathrm{SD})$ for three animals was calculated. Statistical comparisons were made using one-way ANOVA and a post hoc Tukey's pairwise comparison. $P$ values $<0.05$ were considered to be significant.

Combined confocal and electron microscopy. A second set of three male Wistar rats (250 gm; Harlan) were deeply anesthetized with ketamine and xylazine and received unilateral $200 \mathrm{nl}$ stereotaxic injections of $1 \%$ $\mathrm{CTb}$ (Sigma) in the left CVLM as described above. The combined confocal and electron microscopic method we used is a modification of that described by Todd (1997). After a 3 d survival period, the animals were deeply anesthetized with sodium pentobarbitone $(1 \mathrm{ml}$, i.p.) and perfused with saline followed by a fixative containing $4 \%$ formaldehyde, $0.2 \%$ glutaraldehyde, and $0.2 \%$ of saturated picric acid in phosphate buffer, $\mathrm{pH}$ 7.6. L4 segments were removed, placed in the same fixative for $8 \mathrm{hr}$ and cut into $50 \mu \mathrm{m}$ horizontal sections with a Vibratome. The sections were treated with $50 \%$ ethanol for 30 min to improve antibody penetration and also with $1 \%$ sodium borohydride for $30 \mathrm{~min}$ to counteract the effects of glutaraldehyde. Sections were incubated for $3 \mathrm{~d}$ at $4^{\circ} \mathrm{C}$ in guinea pig anti- $\alpha_{2 \mathrm{C}}-\mathrm{AR}$ antiserum (1:500; Neuromics), rabbit antiNK-1 antiserum (1:10,000; Sigma), and a goat anti-CTb antiserum (1: 5,000; List Laboratories). Sections were then rinsed in PBS and placed for $1 \mathrm{~d}$ in a cocktail of donkey secondary antibodies, which consisted of rhodamine-red-anti-guinea pig IgG, FITC-anti-rabbit IgG, cyanine 5.18-anti-goat $\operatorname{IgG}$ (all 1:100), and biotinylated anti-guinea pig $\operatorname{IgG}(1$ : 500; Jackson ImmunoResearch). Primary and secondary antibodies were diluted in detergent-free PBS. After rinsing in PBS, sections were incubated in avidin-biotin-HRP complex (1:1000; Vector Laboratories) for $1 \mathrm{~d}$. Once the sections were mounted, they were scanned with the confocal microscope and lamina I cells were selected for analysis. Six NK-1 receptor-immunoreactive $\mathrm{CTb}$-labeled neurons (two from each animal), which received multiple contacts from $\alpha_{2 \mathrm{C}}$-AR-immunoreactive terminals, were examined. Optical sections were gathered sequentially to avoid bleedthrough. Multiple scans were performed with a $60 \times$ oil-immersion lens at $0.5 \mu \mathrm{m}$ intervals in the $z$-axis and a zoom factor of 1.5 to produce a montage of each selected neuron. In addition, scans with a $40 \times, 20 \times$, $10 \times$, and $4 \times$ lenses were performed to gather progressively lower power images that would serve as a frame of reference for identification of each cell with the electron microscope.

Sections containing scanned cells were removed from the slides and processed for electron microscopy. After rinsing, they were reacted with 


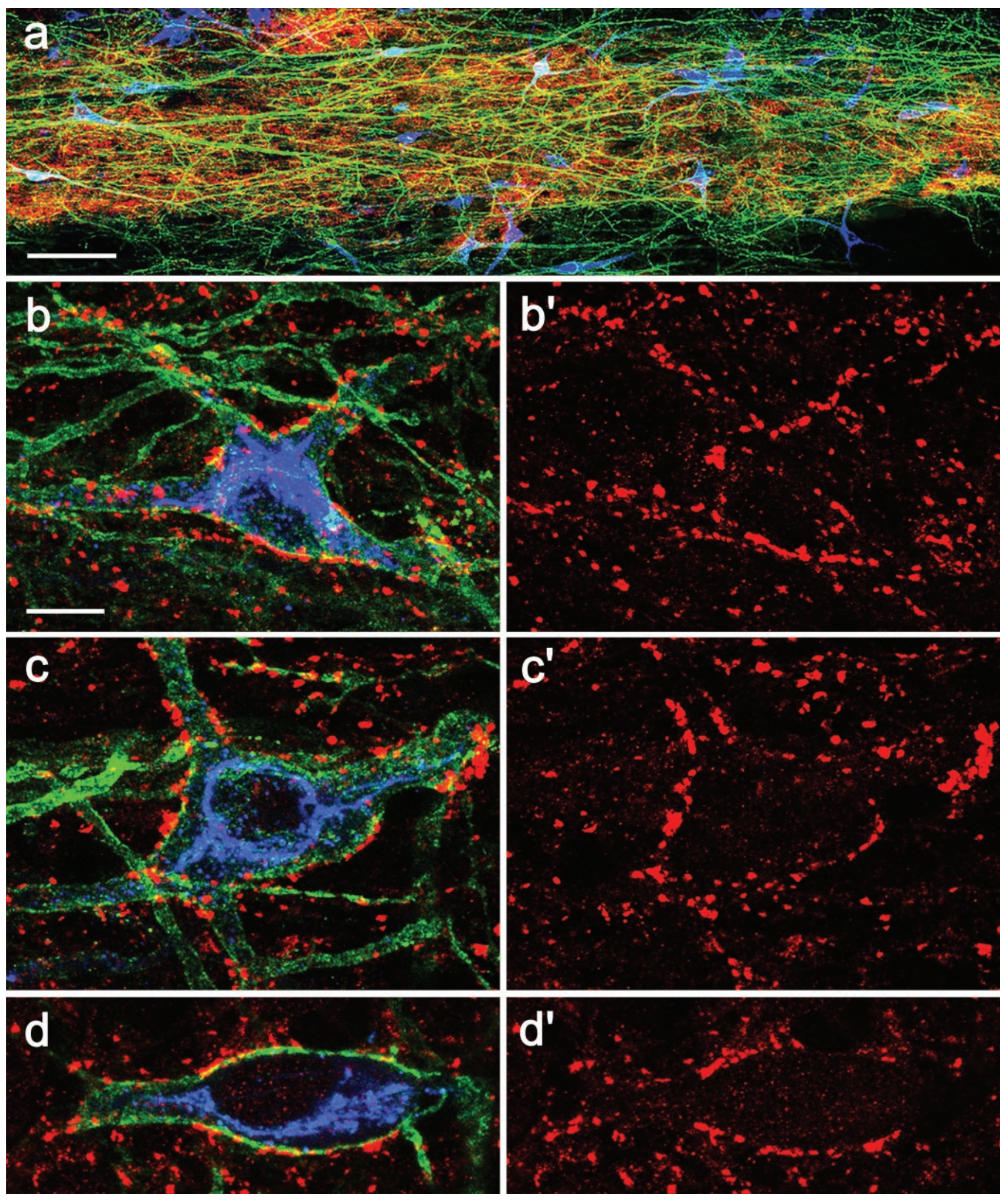

Figure 2. Confocal microscopic images of immunoreactivity for CTb, the NK-1 receptor, and $\alpha_{2 c}$-AR in a horizontal section. $a$, Merged image of a horizontal section of lamina I (blue, CTb; green, NK-1 receptor; red, $\alpha_{2 c}-$ AR) illustrating the general pattern of triple labeling at a low magnification (made from 20 projected confocal images gathered at $1 \mu \mathrm{m}$ steps with a $20 \times$ lens). $b-d$, Projected images of three retrogradely labeled neurons at high magnification (built from 15,10 , and 5 single optical sections for $b$, $c$, and $d$, respectively. Optical sections were gathered at $0.5 \mu \mathrm{m}$ steps with a $40 \times$ lens). Cells shown in $b$ and c are multipolar, whereas the cell shown in $d$ is fusiform. Colors are keyed as in $a$. All three neurons receive multiple contacts from $\alpha_{2 c}$-ARimmunoreactive terminals. $b^{\prime}-d^{\prime}, \alpha_{2 c}$-AR immunoreactivity corresponding to $b-d$, respectively. Note that $\alpha_{2 c}$-AR terminals delineate the cell bodies and dendrites of these neurons. Scale bars: $a, 100 \mu \mathrm{m} ;$ (in $b) b-d, b^{\prime}-d^{\prime}, 10 \mu \mathrm{m}$. 
$3,3^{\prime}$-diaminobenzidine $(\mathrm{DAB})$ in the presence of hydrogen peroxide. They were then placed in a $1 \%$ solution of osmium tetroxide for $30 \mathrm{~min}$, dehydrated in acetone, stained en bloc with uranyl acetate and finally flat-embedded in Durcupan resin (Fluka, Buchs, Switzerland) between cellulose acetate sheets. Sections were examined with a light microscope to establish the location of each cell; DAB-positive $\alpha_{2 \mathrm{C}}$-ARimmunoreactive terminals surrounding cells and landmarks such as blood vessels were used to identify their location within sections. Sections were mounted onto blocks of cured resin, which were trimmed to include the region containing the cell. Ultrathin sections were cut serially with a diamond knife, collected on Formvar-coated grids, and viewed with an electron microscope (model CM100; FEI Company, Eindhoven, The Netherlands).

Sequential immunocytochemistry. A third set of three male Wistar rats (250 gm; Harlan) was used for this part of the study. The initial procedure applied was identical to that described in the section above for confocal microscopy. When scanning of selected double-labeled neurons with contacts from $\alpha_{2 \mathrm{C}}$-AR-immunoreactive terminals was complete, sections were retrieved from the slides and re-incubated in a fourth antiserum: rabbit anti-VGLUT2 antiserum (1:5000; Synaptic Systems, Göttingen, Germany) for $48 \mathrm{hr}$. They were then rinsed and incubated for $3 \mathrm{hr}$ in a solution containing donkey anti-rabbit IgG coupled to FITC (1:100, Jackson Immunoresearch). Finally, sections were remounted and the same neurons that had been scanned previously were identified and scanned again. The same secondary antibody was used to reveal the rabbit anti-NK-1 and rabbit anti-VGLUT2 primary antibodies, but by comparing the FITC labeling before and after the re-incubation in the VGLUT2 antiserum, we could detect the additional FITC labeling, which represents immunoreactivity for VGLUT2. No additional immunoreactivity was observed in control experiments when the VGLUT2 antibody was omitted in the sequential reaction. Equally, the pattern of immunostainning was not altered when performing the sequential incubation in a reverse order for the NK-1 and VGLUT2 labeling (i.e., first incubation containing the rabbit anti-VGLUT2 antiserum in the cocktail of primary antisera followed by sequential incubation in rabbit anti-NK-1 antiserum).

\section{Results}

NK-1 spinomedullary neurons are innervated by axons that possess the $\alpha_{2 \mathrm{C}}-\mathrm{AR}$

Spinomedullary neurons were labeled by injection of the retrograde tracer CTb in the left CVLM. Figure 1 shows the injection site for one of the experiments and an example of the extent of the tracer spread in another experiment. As predicted, numerous retrogradely labeled neurons were found in lamina I and lamina III/IV of the spinal dorsal horn, especially contralateral to the injection site (Todd et al., 2000). A large proportion of CTb-labeled neurons was present in lamina I along with immunoreactivity for the NK-1 receptor and axon terminals possessing the $\alpha_{2 \mathrm{C}}$-AR (Figs. $2 a$, $3 a$ ). At high magnification it was possible to identify NK-1 projection cells by the presence of CTb within them and to study their relationship with $\alpha_{2 \mathrm{C}}$-AR-immunoreactive profiles. Cell bodies and proximal dendrites of lamina I cells frequently received large numbers of contacts from $\alpha_{2 \mathrm{C}}$-AR-immunoreactive structures (Figs. $2 b-d, 3 c$ ), as did distal dendrites of labeled cells in lamina III/IV, which extended dorsally into lamina I (Fig. $3 b, d-f$ ). More than half of the NK-1 projection cells were found to receive contacts from $\alpha_{2 \mathrm{C}}$-AR terminals (average $\pm \mathrm{SD}, 57.3 \pm 5.26 \%$ ).

\section{Distribution and density of $\alpha_{2 C}-\mathrm{AR}$ contacts on NK-1 projection neurons}

The distribution of $\alpha_{2 \mathrm{C}}$-AR contacts was studied in the two populations of NK-1 projection neurons. The neurons were sampled from parasagittal sections that were contralateral to the injection
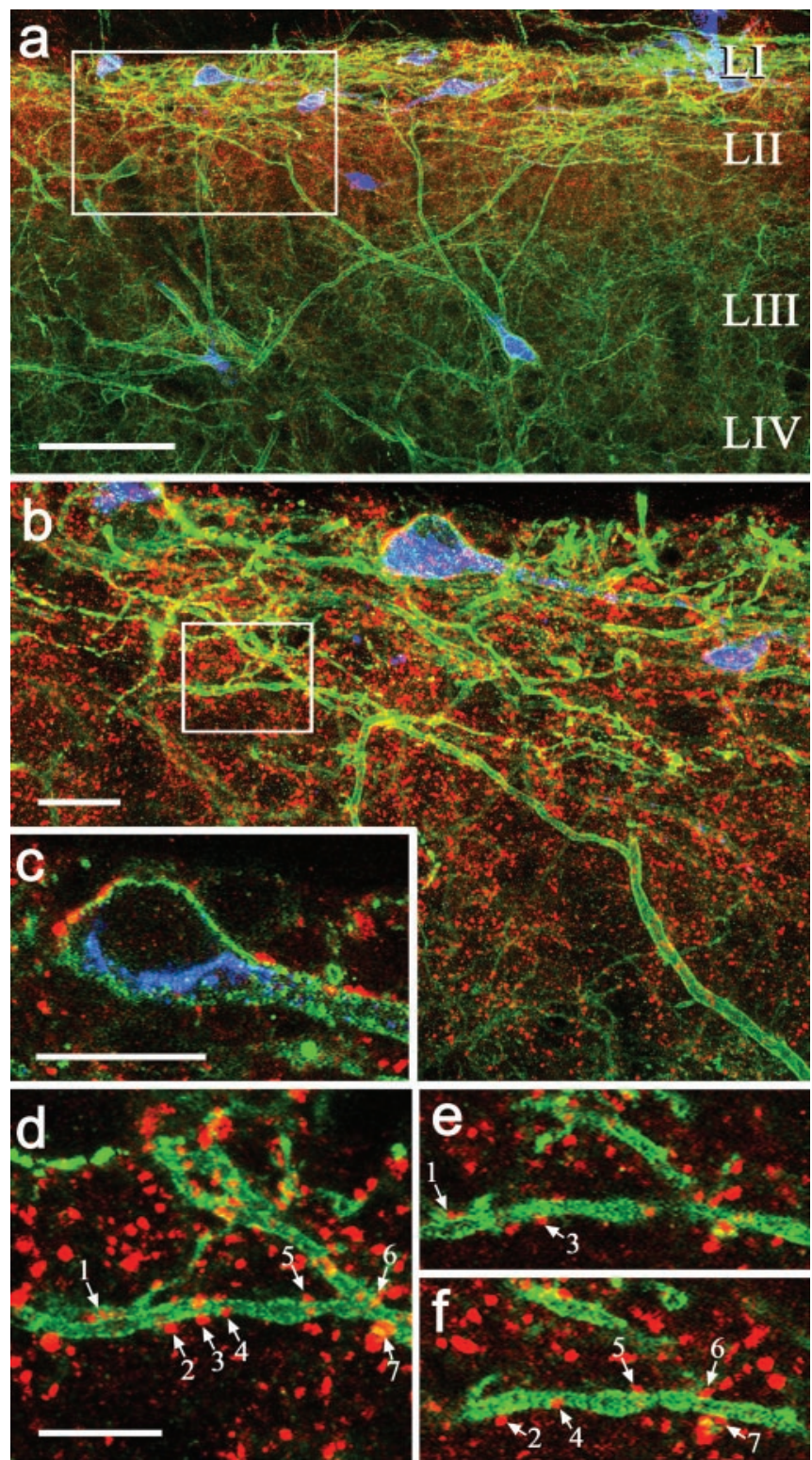

Figure 3. Labeling of CTb, the NK-1 receptor, and $\alpha_{2 C}$-AR in a parasagittal section. $a$, Projected image of a parasagittal section built from 30 confocal images, which were gathered at 1 $\mu \mathrm{m}$ steps with a $20 \times$ lens (colors as in Fig. 2). The locations of laminae I to IV are indicated on the right side of the image. A cell that is labeled with CTb and the NK-1 receptor can be observed in lamina III. This cell has three dorsally oriented dendrites that extend into lamina I. $b$, Projected image at high magnification showing the boxed area in $a$, which includes one of the dorsal dendrites from the lamina III cell (made from 20 optical sections, gathered at $0.5 \mu \mathrm{m}$ steps with a $60 \times$ lens). $c$, Single optical section showing that $\alpha_{2 c}$-AR terminals form contacts on the lamina I cell seen in $b$, which contains CTb and is labeled for the NK-1 receptor. $d$, Projected image of the boxed area in $b$ (built from 7 optical sections, gathered at $0.5 \mu \mathrm{m}$ steps with a $60 \times$ lens); seven boutons, indicated by the numbered arrows, form appositions with the NK-1-positive dendrite, which belongs to the lamina III cell seen in $a$. Appositions are shown in single optical sections: 1 and 3 in $e$, and 2, 4-7 in f. Scale bars: $a, 100 \mu \mathrm{m} ; b, c, 20 \mu \mathrm{m}$; (in d) $d-f, 10 \mu \mathrm{m}$.

site. A sample of 30 lamina I neurons was scanned (10 from each of the three experiments), whereas the sample of lamina III/IV neurons was reduced to 15 (5 from each experiment) because they were found less frequently. The intensity of immunostaining for the NK-1 receptor varied from cell to cell, and although some neurons were very strongly labeled, others were weakly labeled. Neurons showing any evidence of NK-1 receptor immunoreac- 


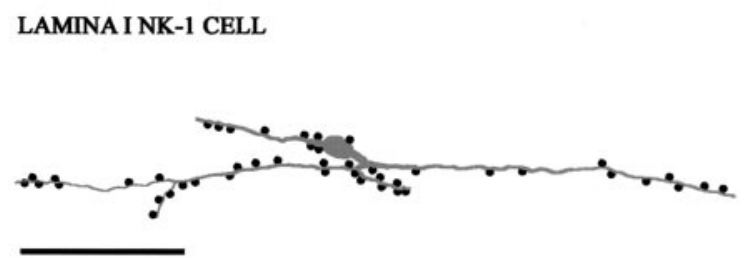

\section{LAMINA III/IV NK-1 CELL}

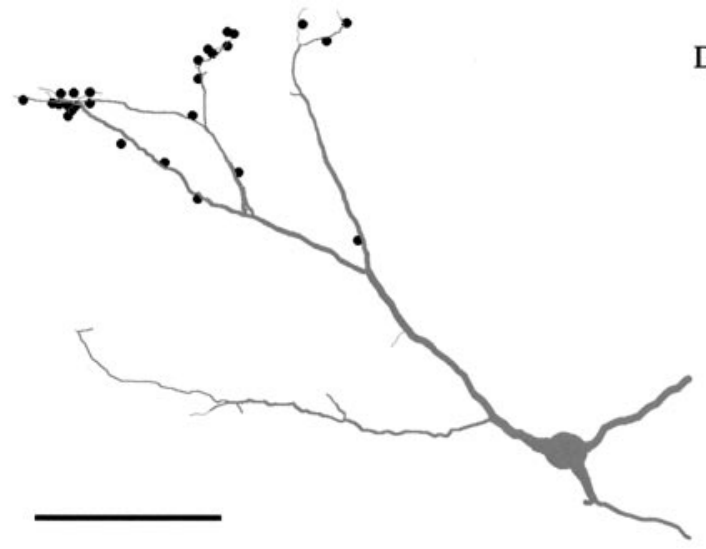

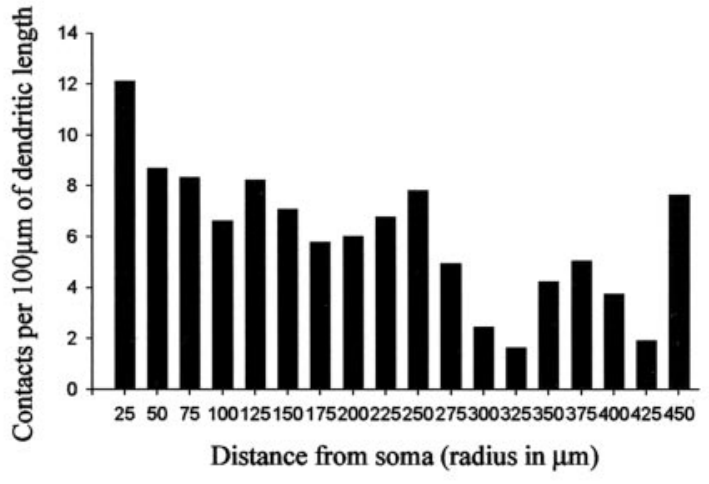

Distribution of $\alpha 2 \mathrm{c}-\mathrm{AR}$ contacts on NK-1 projection cells in Lamina III/IV

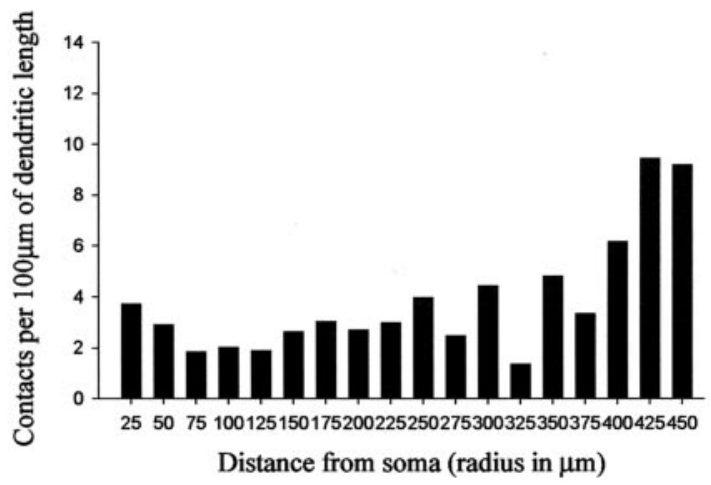

Figure 4. Distribution of $\alpha_{2 C}$-AR contacts on NK-1 projection cells. Left, Two examples of NK-1 projection cells reconstructed with Neurolucida. Contacts (filled circles) from $\alpha_{2 c}$-ARimmunoreactive puncta were mapped on the reconstructions. A lamina I cell is shown above and a lamina III/IV cell bellow. Scale bars, $100 \mu \mathrm{m}$. Right, Histograms summarizing the Sholl analysis of the distribution of $\alpha_{2 c}$-AR contacts on both populations of cells (lamina I, $n=15$; lamina III/IV, $n=30$ ). The number of contacts per $100 \mu \mathrm{m}$ of dendritic length is plotted against the distance from the soma, where $0 \mu \mathrm{m}$ represents the cell body and the consecutive numbers represent the radii of the concentric shells, which increase at $25 \mu \mathrm{m}$ intervals.

tivity were included in the analysis. On average ( \pm SD) $83 \pm$ $16.7 \%$ of the retrogradely labeled neurons were NK-1-positive. Once the neurons were scanned they were reconstructed and the $\alpha_{2 \mathrm{C}}$-AR contacts were mapped (examples in Fig. 4). Sholl analysis of the distribution of $\alpha_{2 \mathrm{C}}$-AR contacts revealed that NK-1 projection neurons with somata in lamina I receive numerous $\alpha_{2 \mathrm{C}}$-AR contacts on cell bodies and proximal dendrites, whereas NK-1 projection neurons with somata in lamina III/IV receive most $\alpha_{2 \mathrm{C}}$-AR contacts on distal dendrites that extend into lamina I-II. The average number of contacts per $100 \mu \mathrm{m}$ of dendritic length was higher for lamina I neurons than for lamina III/IV neurons (average $\pm \mathrm{SD}, 109.3 \pm 38.1$ and $69.3 \pm 20.7$, respectively) (Fig. 4, histograms). We also calculated average densities of $\alpha_{2 \mathrm{C}}$-AR contacts per unit area $\left(100 \mu \mathrm{m}^{2}\right)$ of dendritic surface for lamina I and lamina III/IV NK-1 projection cells to compare them with a population of $\mathrm{PKC} \gamma$-immunoreactive interneurons (Fig. 5). Dendrites of lamina I cells had approximately seven times the density of contacts associated with PKC $\gamma$ cells (average \pm SD contacts per $100 \mu \mathrm{m}^{2}, 1.09 \pm 0.07$ and $0.14 \pm 0.01$, respectively) and lamina III/IV cells were associated with three times the density $\left(0.51 \pm 0.09\right.$ contacts per $\left.100 \mu \mathrm{m}^{2}\right)$. Statistical comparisons confirm that these differences are significant $(p<0.001$, ANOVA; individual differences between all three groups were significant at $p<0.05$, Tukey's post hoc pairwise comparison).
Axon terminals containing the $\alpha_{2 \mathrm{C}}$-AR form synapses with $\mathrm{NK}-1$ projection neurons in lamina I

The combined confocal and electron microscopic method allowed us first to visualize $\alpha_{2 \mathrm{C}}$-AR terminals forming appositions on NK-1 spinomedullary neurons, and second, after processing of the tissue for electron microscopy, to determine if such terminals formed synapses with the neuron (Fig. 6). In total, six neurons were examined (two from each animal), which received 45 appositions from $\alpha_{2 \mathrm{C}}$-AR terminals. Electron microscopic analysis confirmed that 42 of these formed synapses with the neurons. Most of these synapses could be classified as asymmetric, but occasionally it was difficult to define the type of synapse. The remaining three appositions were not observed to form synapses. Synaptic boutons contained circular agranular vesicles and often granular vesicles also (Fig. 6).

$\alpha_{2 \mathrm{C}}-\mathrm{AR}$ axon terminals that innervate NK-1 spinomedullary projection neurons are excitatory

Sequential immunocytochemistry with a fourth antibody against VGLUT2 enabled us to determine if $\alpha_{2 \mathrm{C}}$-AR-immunoreactive profiles forming appositions with NK-1 projection cells were immunoreactive for VGLUT2 (Takamori et al., 2000; Varoqui et al., 2002). A sample of $30 \mathrm{NK}-1$ retrogradely labeled lamina I neurons was scanned (10 from each of the three animals) from the side contralateral to the injection. An average ( \pm SD) of $43 \pm 12$ 


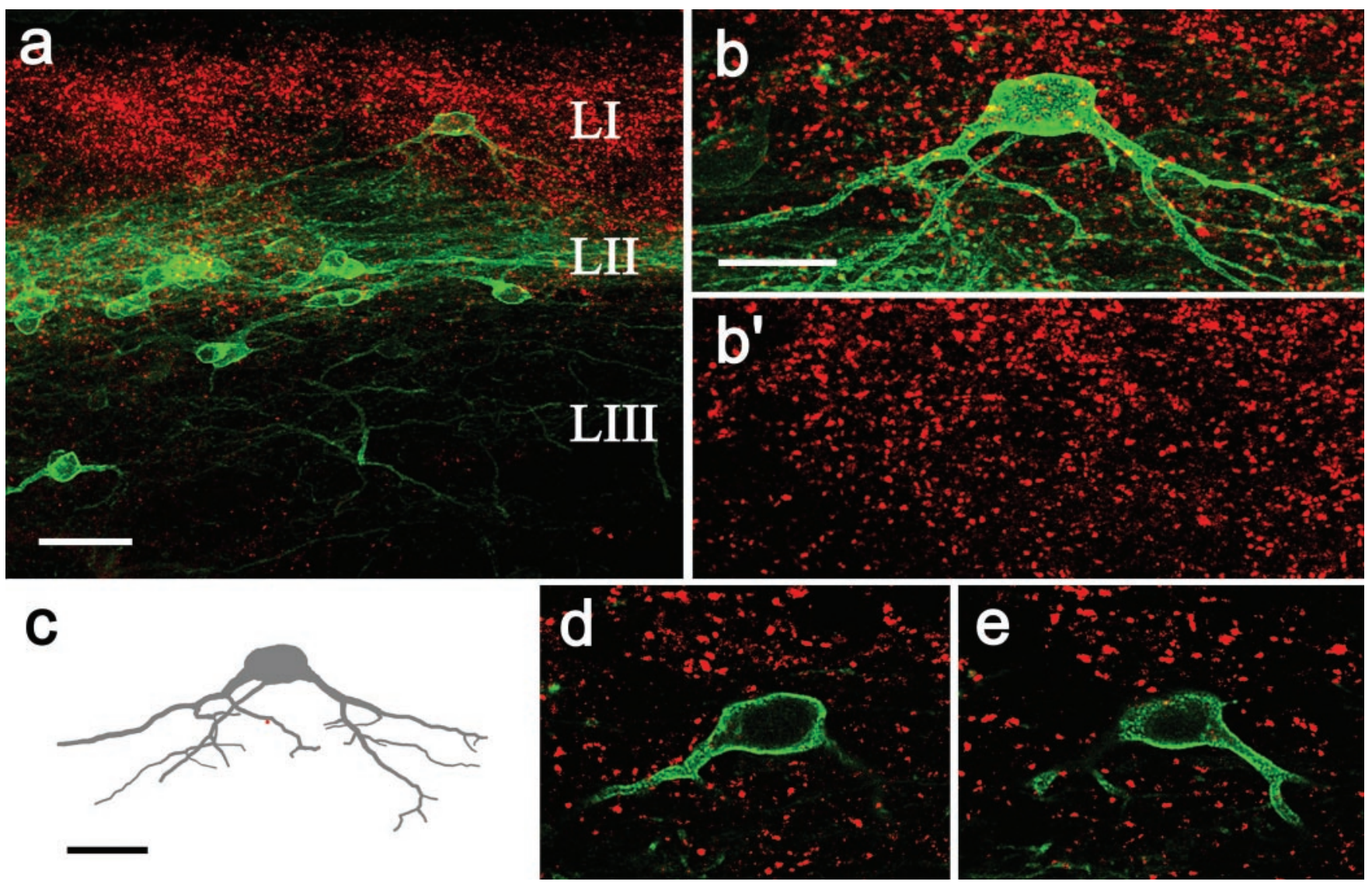

Figure 5. Labeling of PKC $\gamma$ and the $\alpha_{2 c}$-AR in a parasagittal section. a, Projected image of a parasagittal section showing immunoreactivity for PKC $\gamma$ and the $\alpha_{2 c}-A R$ (green and red, respectively) at low magnification (made from 20 single optical sections, gathered at $0.5 \mu \mathrm{m}$ steps with a $20 \times$ lens). The location of laminae I-III is indicated on the right side of the image. A PKC $\gamma$ immunoreactive cell can be seen in lamina I, dorsal to the main PKC $\gamma$ plexus in lamina II. Note that $\alpha_{2 c}$-AR immunoreactivity is dense in the superficial dorsal horn, in which dorsal PKC $\gamma$ cells are

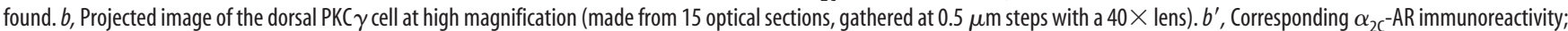
note that $\alpha_{2 c}$-AR terminals do not delineate the outline of the cell. c, Reconstruction of the dorsal cell illustrated in $a$ and $b$; only one $\alpha_{2 c}$-AR terminal was found to form a contact (red circle) with the cell. $d$, e, Single optical sections extracted from the $z$-series in $b$, illustrating the paucity of contacts formed by $\alpha_{2 c}$-AR terminals with the cell body and dendrites of the PKC $\gamma$ cell. Scale bars: $a$, $40 \mu \mathrm{m} ;$ (in $b) b, b^{\prime}, d, e, 20 \mu \mathrm{m} ; c, 20 \mu \mathrm{m}$.

$\alpha_{2 \mathrm{C}}$-AR appositions per neuron was recorded. Of these appositions, $100 \%$ were found to be VGLUT2-positive when the selected neurons were rescanned after the sequential incubation in VGLUT2 antiserum (Fig. 7).

\section{Discussion}

The major finding of this study is that axon terminals containing the $\alpha_{2 \mathrm{C}}$-AR densely innervate NK-1 spinomedullary neurons that project to the CVLM. Both lamina I and lamina III/IV projection neurons were associated with $\alpha_{2 \mathrm{C}}$-AR contact densities that were significantly greater than contact densities on interneurons possessing PKC $\gamma$ immunoreactivity; we conclude that this represents a specific type of arrangement that has not arisen merely by chance. Terminals were concentrated around cell bodies and proximal dendrites of lamina I neurons, whereas in lamina III/IV neurons they were apposed predominantly to distal dendrites, which extended dorsally into laminae I and II. We were able to demonstrate that axon terminals possessing the $\alpha_{2 \mathrm{C}}-\mathrm{AR}$ form synapses with NK-1 projection neurons in lamina I, and that they are likely to have an excitatory action because they also contained VGLUT2, which is a marker for glutamatergic axon terminals (Takamori et al., 2000; Varoqui et al., 2002; Todd et al., 2003). On this basis, we conclude that our hypothesis is correct and that axons of excitatory interneurons possessing $\alpha_{2 \mathrm{C}}$-ARs do indeed target nociceptive projection neurons.

\section{Identification of NK-1 projection neurons}

Our quantitative analysis was confined to neurons contralateral to the CVLM injection site that were NK-1-positive because neurons of this type are very likely to be involved in the transmission of nociceptive information (Naim et al., 1997; Todd et al., 2002). Stereotaxic injections were made into the CVLM because this region of the brainstem is known to receive substantial input from lamina I (Lima et al., 1991; Craig, 1995) and also because lamina I neurons labeled from the CVLM are more numerous than those labeled from other projection targets (i.e., dorsal reticular nucleus, periaqueductal gray, or thalamus; Marshall et al., 1996; Todd et al., 2000). Most spinomedullary neurons labeled from the CVLM project contralaterally, and only a minority project ipsilaterally. Neurons retrogradely labeled from the CVLM also include a population of lamina III/IV cells, which have dorsally directed dendrites that terminate in lamina I. Double-labeling studies indicate that most CVLM neurons also have collateral projections to the lateral parabrachial area (Todd, 2002); therefore, many of the cells analyzed in this study are likely to project to this area in addition to the CVLM. Both these regions of the brainstem are known to be targets of nociceptive neurons and are intimately involved in nociceptive processing (Gauriau and Bernard, 2002; Lima et al., 2002). 

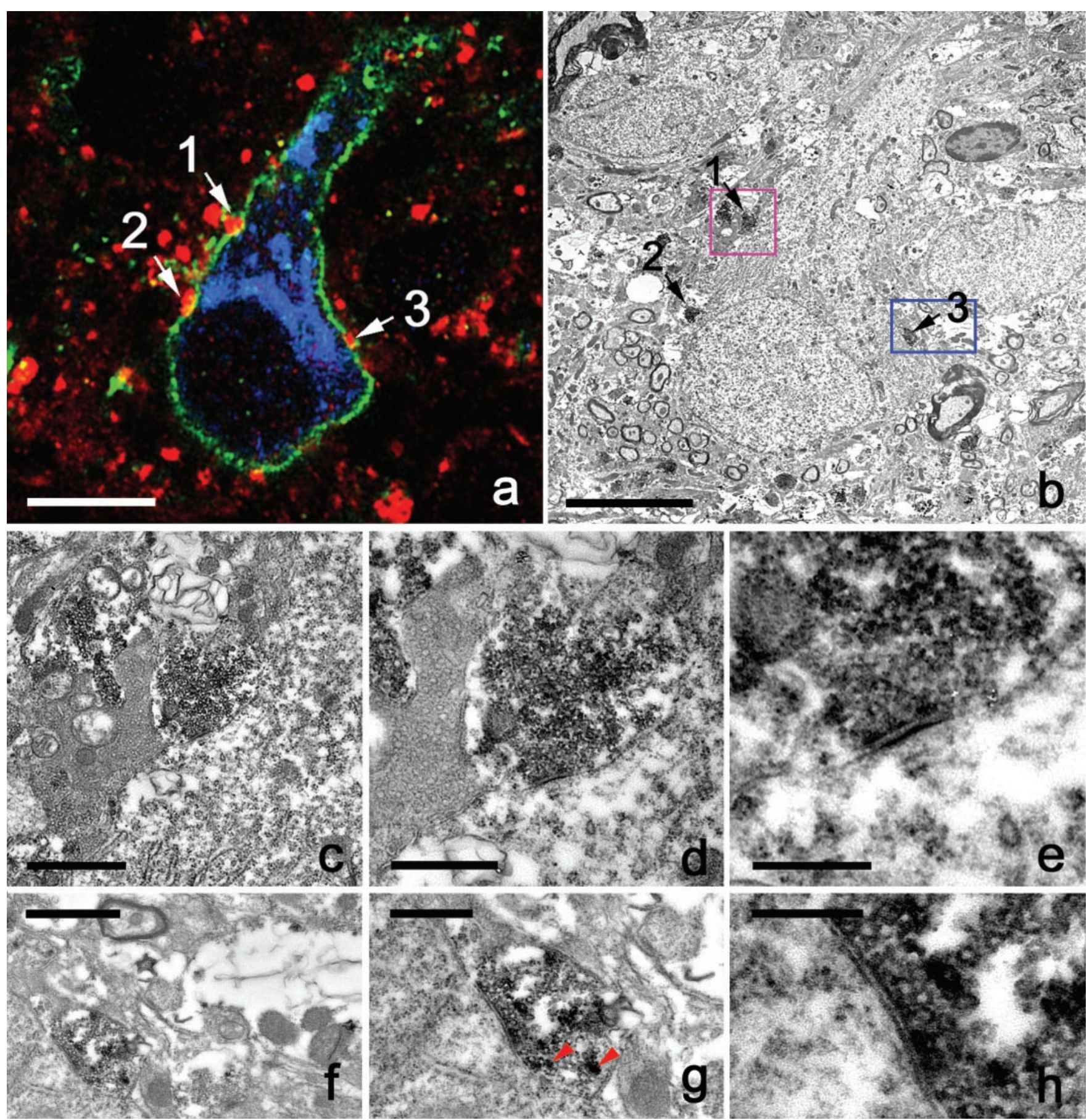

Figure 6. Combined confocal and electron microscopy of $\alpha_{2}$-AR contacts. a, Single optical section of a NK-1 projection cell in lamina I, which is apposed by three $\alpha_{2}{ }^{-A R}$-immunoreactive terminals (arrows numbered 1-3; blue, (Tb; green, NK-1 receptor; red, $\alpha_{2}$-AR). $b$, Electron micrograph of the same cell. The $\alpha_{2 c}$-AR-immunoreactive terminals can be recognized by the dark DAB-reaction product. The three terminals indicated by the arrows (numbered 1-3) correspond to those indicated in $a$. The areas delineated by the purple and blue boxes in $b$ are shown at higher magnification in c and $f$, respectively. $c-e$, Progressively magnified images of the axon terminal indicated by arrow 1 . This forms an asymmetric synapse with a proximal dendrite of the cell. $f-h$, Progressively magnified images of the terminal indicated by arrow 3 . This bouton forms a long asymmetric synapse. Boutons contained circular agranular vesicles and often also granular vesicles (red arrowheads in $g$ ). Scale bars: $a, b, 10 \mu \mathrm{m} ; c, f, 1 \mu \mathrm{m} ; d, g, 0.5 \mu \mathrm{m} ; e, h, 0.25 \mu \mathrm{m}$.

\section{Origin of $\alpha_{2 C^{-A R} \text { axons }}$}

It is probable that the majority of $\alpha_{2 \mathrm{C}}-\mathrm{AR}$ axons in the spinal cord originate from interneurons. Three lines of evidence support this view. First, $\alpha_{2 C}$-AR immunoreactivity is not reduced after rhizotomy or capsaicin treatment, and it is not associated with markers that identify primary afferent terminals (Stone et al., 1998; Olave and Maxwell, 2002, 2003). Second, many $\alpha_{2 C}$-AR- immunoreactive terminals also contain peptides such as enkephalin, somatostatin, neurotensin, and neuropeptide $Y$, which are mainly or exclusively found in spinal interneurons (Stone et al., 1998; Olave and Maxwell, 2002). Third, VGLUT2 is found in the terminals of most $\alpha_{2 \mathrm{C}}$-AR-axons (Olave and Maxwell, 2003), and it is predominantly associated with spinal interneurons (Todd et al., 2003). 

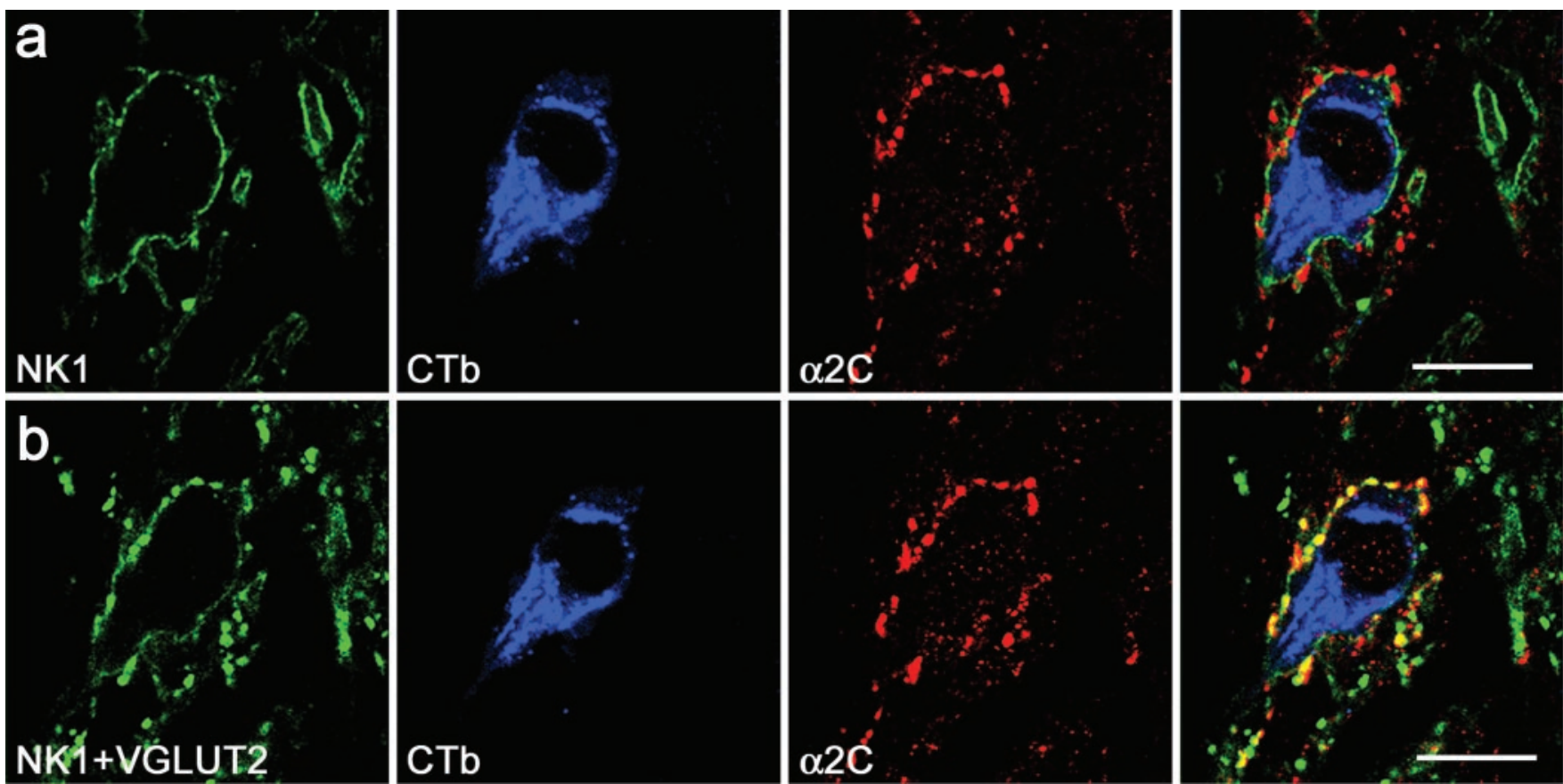

Figure 7. Sequential immunocytochemistry for VGLUT2. a, A single optical section of a NK-1 projection cell from lamina I that receives numerous contacts from $\alpha_{2 c}$-AR terminals. Immunoreactivity for the NK-1 receptor (NK1), $\mathrm{CTb}(\mathrm{CTb})$, and $\alpha_{2 c}-\mathrm{AR}(\alpha 2 \mathrm{C})$ are shown independently. A merged image formed from the previous three is shown on the right. $b$, A single optical section of the same cell that has been rescanned after sequential incubation with a fourth antibody against VGLUT2. The extra-green labeling present in $b$, which was absent in $a$, corresponds to the additional VGLUT2-immunostaining (see NK1 +VGLUT2). Note that all $\alpha_{2 C}$-AR-immunoreactive terminals, which form appositions on the NK-1 projection cell, are immunoreactive for VGLUT2 (yellow profiles in $b$, merged image on the right) and hence can be considered to be excitatory glutamatergic terminals. Scale bars, $20 \mu \mathrm{m}$.

\section{Functional significance of $\alpha_{2 \mathrm{C}}$-AR-innervation of NK-1 projection neurons}

Our findings indicate that NE can influence NK-1 projection neurons through a presynaptic action on axon terminals that possess $\alpha_{2 \mathrm{C}}$-ARs. Both lamina I and lamina III/IV NK-1 projection cells receive dense innervation from small-diameter primary afferent fibers that contain a combination of substance $\mathrm{P}$ and glutamate (De Biasi and Rustioni, 1988; Naim et al., 1997; Todd et al., 2002). Glutamate is undoubtedly involved in acute pain signaling mechanisms, but the role of substance $\mathrm{P}$ in nociceptive transmission is subtle. Ablation of lamina I NK-1 cells attenuates the development of thermal and mechanical hyperalgesia (Mantyh et al., 1997; Khasabov et al., 2002), and mice that lack the NK-1 receptor do not display the characteristic amplification and intensity coding of nociceptive reflexes (De Felipe et al., 1998). Such "knock-out" animals also have reduced descending inhibition evoked by peripheral noxious stimuli (Bester et al., 2001), indicating that NK-1 neurons are components of an ascendingdescending antinociceptive loop. The NK-1 receptor is implicated directly in the mediation of NE antinociception because genetically engineered mice that lack NE show a substance P-dependent chronic hyperalgesia (Jasmin et al., 2002). These lines of evidence suggest that NK-1 neurons are likely to be components of the circuitry that underlies NE antinociception. NE descending inhibitory systems could be recruited by NK-1 spinomedullary neurons, because these cells terminate in a region close to the lateral reticular nucleus that contains dopamine $\beta$-hydroxylaseimmunoreactive neurons, which in turn, project to the spinal dorsal horn (Lee et al., 2001).

It is well established that the antinociceptive action of NE is mediated by $\alpha_{2}$-ARs (Howe et al., 1983; Yaksh, 1985; Proudfit, 1988 ), but it has been shown only recently that both $\alpha_{2 \mathrm{~A}}$-AR and $\alpha_{2 \mathrm{C}}$-AR subtypes are involved in this process (Stone et al., 1997;
Li and Eisenach, 2001; Fairbanks et al., 2002). Budai et al. (1998) reported that periaqueductal gray neurons inhibit nociceptive dorsal horn cells by a presynaptic action on $\alpha_{2}$-ARs. Our findings also support this proposal, because we have shown that $\alpha_{2 \mathrm{C}}$-ARs are located on axon terminals that are presynaptic to nociceptive cells. In addition, virtually all of these terminals are likely to be glutamatergic because they are immunoreactive for VGLUT2 and therefore would be expected to have an excitatory action on their target cells. This finding is also in agreement with studies reporting that activation of $\alpha_{2}$-ARs can reduce the release of glutamate. Pan et al. (2001) showed that the $\alpha_{2}$-AR agonist clonidine inhibits glutamatergic synaptic input to spinal neurons in outer lamina II by a presynaptic action on $\alpha_{2}$-ARs. The $\alpha_{2 \mathrm{~A}}$ and $\alpha_{2 \mathrm{C}^{-}}$ ARs differ not only in their cellular location in the dorsal horn, but also in their affinity for NE and deactivation kinetics. The $\alpha_{2 \mathrm{C}}$-AR has a greater affinity for NE than the $\alpha_{2 \mathrm{~A}}$-AR and the $\alpha_{2 \mathrm{C}}$-AR shows slower deactivation after NE stimulation (Bunemann et al., 2001). These differences suggest that each subclass has distinct physiological functions, even if both types of receptor are implicated in NE antinociception. Our results indicate that part of the antinociceptive action of NE could be mediated via $\alpha_{2 \mathrm{C}}$-ARs present on terminals of excitatory spinal interneurons that are presynaptic to nociceptive neurons in lamina I and distal dendrites of presumed nociceptive neurons in lamina III/IV.

Both presynaptic actions on primary afferent terminals (Kuraishi et al., 1985; Kamisaki et al., 1993) and postsynaptic actions on dorsal horn cells (Davies and Quinlan, 1985; Fleetwood-Walker et al., 1985) have been proposed as mechanisms for NE modulation of nociceptive transmission through $\alpha_{2}$-ARs. In this study we suggest that a third mechanism can also operate (i.e., that NE modulates transmission at terminals of interneurons). We propose that these three mechanisms operate in a complementary manner. It is likely that both $\alpha_{2 \mathrm{~A}}$-ARs located 


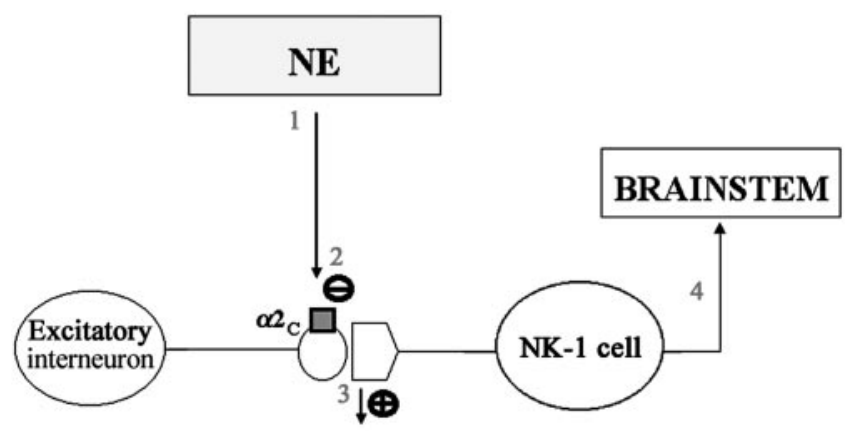

Figure 8. A model of a possible mechanism of noradrenergic antinociception mediated by

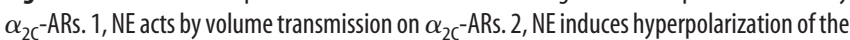
excitatory interneuron axon terminal by acting on $\alpha_{2}$-ARs. 3, Reduction in the efficacy of synaptic transmission results in 4 , inhibition of supraspinal transmission of nociceptive information

on primary afferent terminals and $\alpha_{2 \mathrm{C}}$-ARs on interneuron terminals and dorsal horn cells (Rosin et al., 1996; Stone et al., 1998) are involved in these modulatory processes. In the superficial dorsal horn, there is a dense plexus of NE fibers (Rajaofetra et al., 1992 ) that widely overlaps with areas of intense $\alpha_{2 \mathrm{C}}$-AR immunoreactivity. Noradrenergic axons do not form axo-axonic synapses in this region (Doyle and Maxwell, 1991a,b); indeed, axoaxonic synapses have been found only on primary afferent terminals and are not formed with terminals of interneurons (Alvarez, 1998). Therefore, NE cannot act on interneuron axons through a classic synaptic mechanism, and any interaction with terminals possessing adrenergic receptors must occur via volume transmission.

The NE descending system, along with the serotoninergic system, performs a major role in the regulation of nociceptive transmission in the dorsal horn. However the mechanisms of action of these two monoamines on NK-1 neurons are likely to be different. Many projection cells that possess the NK-1 receptor in lamina I and laminae III/IV are heavily targeted by serotoninimmunoreactive axons, which form numerous contacts with their cell bodies and proximal dendrites (Stewart and Maxwell, 2000; Polgár et al., 2002) but NE contacts on these cells are very sparse indeed (Stewart and Maxwell, 2000; Stewart, 2001). This evidence suggests that serotonin operates directly on NK-1 cells via a postsynaptic action, whereas the effect of NE is more likely to be diffuse and is consistent with our contention that NE operates via volume transmission on interneuron axon terminals.

We propose a model of the possible mechanism of antinociception mediated through $\alpha_{2 \mathrm{C}}$-ARs in Figure 8 . The action of NE on the $\alpha_{2 \mathrm{C}}$-AR would be predicted to induce membrane hyperpolarization (Surprenant et al., 1990; Shen et al., 1992), which would lead to a reduction in the efficacy of synaptic transmission between $\alpha_{2 \mathrm{C}}$-AR-axon terminals of excitatory interneurons and projection neurons. This would selectively suppress excitatory polysynaptic input to these neurons, which, in turn, would attenuate the transmission of nociceptive information to supraspinal structures.

\section{References}

Alvarez FJ (1998) Anatomical basis for presynaptic inhibition of primary sensory fibers. In: Presynaptic inhibition and neural control (Rudomin P, Romo R, Mendell L, eds), pp 13-49. New York: Oxford UP.

Bester H, De Felipe C, Hunt SP (2001) The NK1 receptor is essential for the full expression of noxious inhibitory controls in the mouse. J Neurosci 21:1039-1046.

Budai D, Harasawa I, Fields HL (1998) Midbrain periaqueductal gray
(PAG) inhibits nociceptive inputs to sacral dorsal horn neurons through $\alpha_{2}$-adrenergic receptors. J. Neurophysiol 80:2244-2254.

Bunemann M, Bucheler MM, Philipp M, Lohse MJ, Hein L (2001) Activation and deactivation kinetics of $\alpha_{2 \mathrm{~A}^{-}}$and $\alpha_{2 \mathrm{C}^{-}}$adrenergic receptoractivated $\mathrm{G}$ protein-activated inwardly rectifying $\mathrm{K}^{+}$channel currents. J Biol Chem 276:47512-47517.

Craig AD (1995) Distribution of brainstem projections from spinal lamina I neurons in the cat and monkey. J Comp Neurol 361:225-248.

Davies J, Quinlan JE (1985) Selective inhibition of responses of feline dorsal horn neurones to noxious cutaneous stimuli by tizanidine (DS103-282) and noradrenaline: involvement of $\alpha_{2}$-adrenoceptors. Neuroscience 16:673-682.

De Biasi S, Rustioni A (1988) Glutamate and substance P co-exist in primary afferent terminals in the superficial laminae of spinal cord. Proc Natl Acad Sci USA 85:7820-7824.

De Felipe C, Herrero JF, O’Brien JA, Palmer JA, Doyle CA, Smith AJ, Laird JM, Belmonte C, Cervero F, Hunt SP (1998) Altered nociception, analgesia and aggression in mice lacking the receptor for substance P. Nature 392:394-397.

Doyle CA, Maxwell DJ (1991a) Ultrastructural analysis of noradrenergic nerve terminals in the cat lumbosacral spinal dorsal horn: a dopamine- $\beta$ hydroxylase immunocytochemical study. Brain Res 563:329-333.

Doyle CA, Maxwell DJ (1991b) Catecholaminergic innervation of the spinal dorsal horn: a correlated light and electron microscopic analysis of tyrosine hydroxylase-immunoreactive fibres in the cat. Neuroscience 45:161-176.

Fairbanks CA, Stone LS, Kitto KF, Nguyen HO, Posthumus IJ, Wilcox GL (2002) $\alpha_{2 C}$-Adrenergic receptors mediate spinal analgesia and adrenergic-opioid synergy. J Pharmacol Exp Ther 300:282-290.

Fleetwood-Walker SM, Mitchell R, Hope PJ, Molony V, Iggo A (1985) An $\alpha 2$ receptor mediates the selective inhibition by noradrenaline of nociceptive responses of identified dorsal horn neurons. Brain Res 334:243-254.

Gauriau C, Bernard JF (2002) Pain pathways and parabrachial circuits in the rat. Exp Physiol 87:251-258.

Guo TZ, Davies MF, Kingery WS, Patterson AJ, Limbird LE, Maze M (1999) Nitrous oxide produces antinociceptive response via $\alpha_{2 \mathrm{~B}}$ and/or $\alpha_{2 \mathrm{C}}$ adrenoceptor subtypes in mice. Anesthesiology 90:470-476.

Hoehn K, Reid A, Sawynok J (1988) Pertussis toxin inhibits antinociception produced by intrathecal injection of morphine, noradrenaline and baclofen. Eur J Pharmacol 146:65-72.

Howe JR, Wang JY, Yaksh TL (1983) Selective antagonism of the antinociceptive effect of intrathecally applied alpha adrenergic agonists by intrathecal prazosin and intrathecal yohimbine. J Pharmacol Exp Ther 224:552-558.

Jasmin L, Tien D, Weinshenker D, Palmiter RD, Green PG, Janni G, Ohara PT (2002) The NK1 receptor mediates both the hyperalgesia and the resistance to morphine in mice lacking noradrenaline. Proc Natl Acad Sci USA 99:1029-1034.

Kamisaki Y, Hamada T, Maeda K, Ishimura M, Itoh T (1993) Presynaptic $\alpha 2$ adrenoceptors inhibit glutamate release from rat spinal cord synaptosomes. J Neurochem 60:522-526.

Khasabov SG, Rogers SD, Ghilardi JR, Peters CM, Mantyh PW, Simone DA (2002) Spinal neurons that possess the substance P receptor are required for the development of central sensitization. J Neurosci 22:9086-9098.

Kuraishi Y, Hirota N, Sato Y, Kaneko S, Satoh M, Takagi H (1985) Noradrenergic inhibition of the release of substance $\mathrm{P}$ from the primary afferents in the rabbit spinal dorsal horn. Brain Res 359:177-182.

Lee HS, Waterhouse BD, Mihailoff GA (2001) Evidence that dopamine- $\beta$ hydroxylase immunoreactive neurons in the lateral reticular nucleus project to the spinal cord in the rat. Anat Rec 263:268-279.

Levine JD, Fields HL, Basbaum AI (1993) Peptides and the primary afferent nociceptor. J Neurosci 13:2273-2286.

Li X, Eisenach JC (2001) $\alpha_{2 \mathrm{~A}}$-adrenoceptor stimulation reduces capsaicininduced glutamate release from spinal cord synaptosomes. J Pharmacol Exp Ther 299:939-944

Lima D, Mendes-Ribeiro JA, Coimbra A (1991) The spino-latero-reticular system of the rat: projections from the superficial dorsal horn and structural characterization of marginal neurons involved. Neuroscience 45:137-152.

Lima D, Albino-Teixeira A, Tavares I (2002) The caudal medullary ventrolateral reticular formation in nociceptive-cardiovascular integration. An experimental study in the rat. Exp Physiol 87:267-274. 
Mantyh PW, Rogers SD, Honore P, Allen BJ, Ghilardi JR, Li J, Daughters RS, Lappi DA, Wiley RG, Simone DA (1997) Inhibition of hyperalgesia by ablation of lamina I spinal neurons expressing the substance P receptor. Science 278:275-279.

Marshall GE, Shehab SAS, Spike RC, Todd AJ (1996) Neurokinin-1 receptors on lumbar spinothalamic neurons in the rat. Neuroscience 72:255-263.

Naim M, Spike RC, Watt C, Shebab SA, Todd AJ (1997) Cells in laminae III and IV of the rat spinal cord that possess the neurokinin-1 receptor and have dorsally directed dendrites receive a major synaptic input form tachykinin-containing primary afferents. J Neurosci 17:5536-5548.

Olave MJ, Maxwell DJ (2002) An investigation of neurons that possess the $\alpha_{2 c}$-adrenergic receptor in the rat dorsal horn. Neuroscience 115:31-40.

Olave MJ, Maxwell DJ (2003) Axon terminals possessing the $\alpha_{2 \mathrm{c}}$-adrenergic receptor in the rat dorsal horn are predominantly excitatory. Brain Res 965:269-273.

Pan YZ, Li DP, Pan HL (2001) Inhibition of glutamatergic synaptic input to spinal lamina $\mathrm{II}_{\mathrm{o}}$ neurons by presynaptic $\alpha_{2}$-adrenergic receptors. J. Neurophysiol 87:1938-1947.

Paxinos G, Watson C (1997) The rat brain in stereotaxic coordinates. ed 3. New York: Academic Press.

Polgár E, Fowler JH, McGill MM, Todd AJ (1999) The types of neuron which contain protein kinase $\mathrm{C}$ gamma in rat spinal cord. Brain Res 833:71-80.

Polgár E, Puskár Z, Watt C, Matesz C, Todd AJ (2002) Selective innervation of lamina I projection neurones that possess the neurokinin 1 receptor by serotonin-containing axons in the rat spinal cord. Neuroscience 109:799-809.

Proudfit HK (1988) Pharmacologic evidence for the modulation of nociception by noradrenergic neurons. Prog Brain Res 77:357-370.

Rajaofetra N, Ridet J-L, Poulat P, Marlier L, Sandillon F, Geffard M, Privat A (1992) Immunocytochemical mapping of noradrenergic projections to the rat spinal cord with an antiserum against noradrenaline. J. Neurocytol 21:481-494.

Rosin DL, Talley EM, Lee A, Stornetta RL, Gaylinn BD, Guyenet PG, Lynch KR (1996) Distribution of $\alpha_{2 \mathrm{c}}$ adrenergic receptor like immunoreactivity in the rat central nervous system. J Comp Neurol 372:135-165.

Shen K-Z, North RA, Surprenant A (1992) Potassium channels opened by noradrenaline and other transmitters in excised membrane patches of guinea-pig submucosal neurons. J Physiol (Lond) 445:581-599.

Stewart W (2001) The organization of the monoaminergic and cholinergic systems in the spinal cord. $\mathrm{PhD}$ thesis, University of Glasgow.
Stewart W, Maxwell DJ (2000) Morphological evidence for selective modulation by serotonin of a subpopulation of dorsal horn cells which possess the neurokinin-1 receptor. Eur. J Neurosci 12:4583-4588.

Stone LS, MacMillan LB, Kitto KF, Limbird LE, Wilcox GL. Stone LS, MacMillan LB, Kitto KF, Limbird LE, Wilcox GL (1997) The $\alpha_{2 \mathrm{~A}}$ adrenergic receptor subtype mediates spinal analgesia evoked by $\mathrm{a}_{2}$ agonists and is necessary for spinal adrenergic-opioid synergy. J Neurosci 17:7157-7165.

Stone LS, Broberger C, Vulchanova L, Wilcox GL, Hokfelt T, Riedl MS, Elde $\mathrm{R}$ (1998) Differential distribution of $\alpha_{2 \mathrm{~A}}$ and $\alpha_{2 \mathrm{C}}$ adrenergic receptor immunoreactivity in the rat spinal cord. J Neurosci 18:5928-5937.

Surprenant A, Shen KZ, North RA, Tatsumi H (1990) Inhibition of calcium currents by noradrenaline, somatostatin and opioids in guinea-pig submucosal neurones. J. Physiol. (Lond) 431:585-608.

Takamori S, Rhee JS, Rosenmund C, Jahn R (2000) Identification of a vesicular glutamate transporter that defines a glutamatergic phenotype in neurons. Nature 407:189-194.

Todd AJ (1997) A method for combining confocal and electron microscopic examination of sections processed for double- or triple-labelling immunocytochemistry. J Neurosci Methods 73:149-157.

Todd AJ (2002) Anatomy of primary afferents and projection neurones in the rat spinal dorsal horn with particular emphasis on substance $P$ and the neurokinin 1 receptor. Exp. Physiol 87:245-249.

Todd AJ, McGill MM, Shehab SAS (2000) Neurokinin 1 receptor expression by neurons in laminae I, III and IV of the rat spinal dorsal horn that project to the brainstem. Eur J Neurosci 12:680-700.

Todd AJ, Puskár Z, Spike RC, Hughes C, Watt C, Forrest L (2002) Projection neurons in lamina I of rat spinal cord with the neurokinin 1 receptor are selectively innervated by substance p-containing afferents and respond to noxious stimulation. J Neurosci 22:4103-4113.

Todd AJ, Hughes DI, Polgár E, Mackie M, Ottersen PO, Maxwell DJ (2003) The expression of vesicular glutamate transporters VGLUT1 and VGLUT2 in neurochemically defined axonal populations in the rat spinal cord with emphasis on the dorsal horn. Eur J Neurosci 17:13-27.

Varoqui H, Schafer MK, Zhu H, Weihe E, Erickson JD (2002) Identification of the differentiation- associated $\mathrm{Na}^{+} / \mathrm{PI}$ transporter as a novel vesicular glutamate transporter expressed in a distinct set of glutamatergic synapses. J Neurosci 22:142-155.

Yaksh TL (1985) Pharmacology of spinal adrenergic systems which modulate spinal nociceptive processing. Pharmacol Biochem Behav 22:845858. 